\title{
EL “OTRO JUEZ” Y LA HERMENÉUTICA: EL FICCIONALISMO COMO CRITERIO LEGITIMADOR DE LA DECISIÓN JURÍDICA
}

\author{
THE “OTHER JUDGE” AND HERMENEUTICS: FICCIONALISM AS A \\ LEGITIMATING CRITERION FOR THE JUDICIAL DECISION
}

\section{Diego Pérez Lasserre*}

RESUMEN: El presente trabajo tiene por finalidad proporcionar un criterio legitimador de la decisión jurídica basado en la intersubjetividad de la comunidad de jueces tomando como base el pensamiento de Carl Schmitt, así como de otros filósofos y juristas que se han enfrentado a la misma problemática.

Palabras clave: Criterio legitimador, decisión jurídica, intersubjetividad, Carl Schmitt.

ABSTRACT: The purpose of this paper is to provide a legitimizing criterion of the legal decision based on the intersubjectivity of the community of judges based on Carl Schmitt's thought, as well as other philosophers and jurists who have faced the same problem.

Keywords: Legitimizing criterion, legal decision, intersubjectivity. Carl Schmitt.

\section{INTRODUCCIÓN: DELIMITANDO EL PROBLEMA}

Una idea bastante común en el derecho es aquella que postula que los jueces, en razón del principio de separación de los poderes del Estado ${ }^{1}$, han de limitar su actividad a la aplicación de la ley. Puesto en negativo, los magistrados en caso alguno han de arrogarse facultades legislativas, por lo que les está vedado crear derecho. Ahora bien, aun cuando esta es una noble aspiración que encuentra sus fundamentos en la Teoría Política, su concreción a nivel fáctico muchas veces resulta quimérica. Como bien señala Dworkin, el aterrizaje práctico de esta idea en muchos casos es imposible en razón de la novedad de los casos puestos frente a los jueces. Es decir, la originalidad de los conflictos hace que no sean susceptibles de ser solucionados aun mediante la extensión y reinterpretación de los preceptos legales vigentes ${ }^{2}$. En palabras sencillas, los casos difíciles ${ }^{3}$, como los llama Dworkin, permiten

\footnotetext{
Magíster en Pensamiento Contemporáneo: filosofía y pensamiento político, Universidad Diego Portales. Profesor de Filosofía y Derecho Civil, Facultad de Derecho y Gobierno, Universidad San Sebastián. Dirección postal: Bellavista 7, Recoleta. Dirección electrónica: diego.perezl@uss.cl. Este artículo forma parte del Proyecto Fondecyt Regular $N^{\circ} 1150102$, del cual el autor es tesista.

1 Cf. Dworkin (1978) p. 82.

2 Cf. DWORKIn (1978) p. 82.

3 En este sentido, Dworkin (1978).
} 
dar cuenta de que la operación que realizan los jueces al fallar no consiste meramente en hacer calzar el caso particular bajo las leyes vigentes en un determinado ordenamiento jurídico.

El reconocimiento de la situación recién descrita ha llevado a autores como Gadamer, Derrida y Larenz, entre otros, a afirmar que la interpretación jurídica no consiste en un proceso de mera subsunción del caso bajo el sentido y alcance de las categorías jurídicas que proporcionan los textos legales. Por el contrario, ellos toman una posición hermenéutica según la cual "la «aplicación" de la norma por la jurisprudencia de los tribunales (o también por la conducta coincidente de los miembros de la comunidad jurídica) no deja la norma intacta, sino que sigue determinando duramente su significado concreto, es decir, el contenido normativo" . En un sentido similar, Atria señala que aun cuando "en algunas materias las reglas son las mismas, su aplicación es significativamente diferente" ${ }^{5}$. En otras palabras, el contenido normativo de un texto legal se reconfigura de acuerdo al momento histórico ${ }^{6}$ y a las características particulares del caso que hace necesario acudir a él en primer término. A modo de ejemplo, el sentido y alcance que se le daba a la fuerza como vicio del consentimiento en el contexto del matrimonio no es el mismo hoy que en épocas pasadas, aun cuando las palabras contenidas en el artículo $8^{\circ}$ de la Ley de Matrimonio Civil ${ }^{7}$ no han cambiado.

Ahora, el sostener una posición jurídica/hermenéutica como la recién descrita genera un peligro no menor. Nos referimos a que ella da pie a una lectura según la cual, dado que el contenido normativo de la ley se ve renovado en cada caso particular, el sentido y alcance de un texto legal depende del arbitrio irrestricto del juez. En palabras de García Amado, esta posición hermenéutica "se detiene precisamente allí donde más interesa en derecho la teoría de la interpretación: a la hora de proporcionar pautas del correcto interpretar, cri-

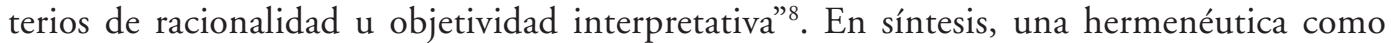
la recién descrita no proporciona a los operadores jurídicos un suelo firme desde el cual se pueda aseverar que una determinada interpretación de un texto legal es correcta.

Este es el contexto en el que se inserta el presente trabajo. En efecto, en él argumentaremos que una posición hermenéutica que le da un sentido configurador al carácter concreto de la existencia sí admite un criterio de corrección de la interpretación en sede jurídica. Así, justificaremos que un criterio basado en el asentimiento "hipotético" de los jueces permite concluir que una interpretación jurídica, y la consecuente aplicación del derecho, es correcta'.

\footnotetext{
4 Larenz (2001) p. 138. En el mismo sentido, Gadamer (2013) pp. 319-320, Rasch (2004) pp. 101-102 y DERrida (1992) p. 152.

5 Atria (2002) p. 351.

En lo que se refiere a la historicidad del derecho, Gerhart Husserl muy lucidamente explica lo siguiente: "que el Derecho «tiene la estructura temporal de la historicidad» significa que no solo «surge» y "perece» en el tiempo (histórico), sino que también participa de la corriente de la Historia, que puede también cambiar con la situación histórica y con los hombres, para lo que tiene «validez»". HusserL (1954) p. 23.

LEY $N^{\circ} 19.947$.

García Amado (2009) p. 192.

Criterio que encuentra sus fundamentos en los pensamientos de Gadamer, Schmitt y Derrida, entre otros.
} 
Ahora, un problema de esta envergadura justifica el introducirse de lleno en discusiones filosóficas y jurídicas de larga data. Sin embargo, dado que la finalidad del presente trabajo se limita a proponer un criterio que permita legitimar la decisión jurídica que le sea útil a la praxis, y no dar respuesta a la pregunta que interroga sobre las condiciones que permiten justificar que una decisión es justa en un sentido sustancial o hacer un recorrido que contraste todas y cada una de las posiciones de los pensadores que se han dedicado a intentar dar respuesta a esta interrogante ${ }^{10}$, solo nos dedicaremos a analizar el pensamiento del filósofo y jurista Carl Schmitt ${ }^{11}$.

\section{EL "OTRO JUEZ" EMPÍRICO: LEY Y JUICIO}

El texto Ley y juicio de Carl Schmitt (1912) nos proporciona ciertos elementos que son de utilidad para la elaboración de un criterio legitimador de la decisión jurídica. Ahora, ¿por qué este texto temprano de Schmitt? Porque, si bien no constituye uno de los textos clásicos de este autor, se hace cargo directamente de la pregunta acerca de la posibilidad de un criterio legitimador de la decisión jurídica. En efecto, en su inicio Schmitt nos previene que "el presente tratado se cuestiona cuando una decisión que emana de la praxis jurídica (Rechtspraxis) es correcta (richtig); y responde diciendo que es a la propia praxis a quien corresponde decidir. Según esto, todo juez se esfuerza verdaderamente por decidir tal y como actualmente se decide en la praxis. A sus esfuerzos por encontrar una decisión correcta, precede siempre la existencia necesaria de una praxis regular y unitaria"12.

En otras palabras, elegimos este texto de Schmitt porque parte de la premisa de que, en pos de la seguridad jurídica, necesario es postular un criterio que asegure un cierto grado de rectitud de la decisión jurídica, pero lo hace desde una perspectiva que reconoce que las leyes han de ser reconfiguradas de acuerdo a los casos que hacen necesario acudir a ellas.

Contextualizando un poco el pensamiento vertido por el filósofo y jurista alemán en esta obra, tenemos que algunas de sus reflexiones sobre hermenéutica jurídica se asemejan bastante a aquellas propias de la hermenéutica existencial de Gadamer. Así, en las primeras páginas de Ley y juicio Schmitt asevera que "no debe buscarse una respuesta absoluta e intemporal a la cuestión de la rectitud de una decisión, que, por ejemplo, se deduzca de la «idea» de la decisión judicial; esto además no tendría tampoco ningún valor práctico. El método de la aplicación del derecho debe descubrir la idea rectora de la praxis actual, y uti-

10 Cabe asimismo mencionar, a modo de prevención, que en este trabajo no se abordarán posiciones que pertenecen a la "Teoría de la argumentación”. Esto, sin embargo, no se debe a un capricho. Por el contrario, responde al hecho de que, como bien lo explica Thulstrup, entre la hermenéutica existencial y los métodos analítico-lingüísticos de la teoría de la argumentación existen diferencias epistemológicas, conceptuales, metodológicas y teleológicas que en sí justificarían un trabajo no menor. Es decir, no se analizan estas posiciones porque la comparación entre ambas tradiciones justifica un trabajo exclusivamente dedicado a dicho objeto, cuestión que no es el fin del presente trabajo. ThuLstrup (1967) p. 44.

11 Cabe tener en consideración que también utilizaremos como insumo a Hans-Georg Gadamer, Jacques Derrida y Karl Larenz.

12 Sснмітт (2012) p. 5. 
lizarla de manera que sirva a modo de una suerte de autorreflexión sobre sus fines y medios. Que la praxis se haga consciente de su sentido supone un progreso científico"13.

Es decir, Schmitt es de la idea de que la solución al problema de la legitimación de la decisión jurídica no está en la elaboración de una dogmática jurídica perfecta que en abstracto elabore una interpretación de la ley a tal punto perfecta que la labor del juez consista en una mera subsunción del caso bajo la norma. En efecto, es posible identificar que Schmitt opera bajo la lógica, muy lucidamente explicada por Karl Larenz, de que "la interpretación de la ley es un proceso constante en el que la idea expresada en la ley es de nuevo pensada y continuada" 14 .

No solo asegura Schmitt que en caso alguno la interpretación jurídica consiste en una operación de mera subsunción, sino que también afirma (en un gesto de clara oposición a la idea kelseniana de un "ciencia pura del derecho") que quien piensa lo contrario desconoce la inabarcabilidad de la realidad por parte de una norma jurídica. Así, Schmitt afirma que "solo una mínima parte de los supuestos que se le ofrecen al juez para dictar sentencia pueden ser resueltos acudiendo al simple y claro contenido de la ley. Sería impensable que se pudiera resumir la regulación exhaustiva de la realidad multiforme de la vida en unos pocos artículos, de los cuales simplemente procediera la interpretación de cada caso concreto. [...]. Pareciera como si el juez debiera ser algo distinto de la boca que pronuncia las palabras de la ley, algo diferente de una máquina de subsumir, de un autómata de la ley o como quiera que se le haya denominado cuando se ha querido menospreciar su función"15.

Puesto de otro modo, la hermenéutica jurídica no puede hacer oídos sordos al carácter contingente de los casos particulares. Por el contrario, el criterio legitimador viene desde y es para la praxis judicial.

¿Qué es, sin embargo, lo que debe buscar este criterio? Puesto de otro modo, ¿cuál ha de ser el objetivo del mismo? Como bien explica Schmitt, en la hermenéutica jurídica un criterio legitimador de la decisión jurídica debe lograr "la mayor probabilidad de [...] <que esta sea> previsible y calculable y, consiguientemente, de que otros jueces hubieran decidido de la misma manera. Siempre se trata del juez, de la praxis judicial"16. Es decir, este criterio debe proveer un marco suficiente de seguridad jurídica, lo que se traduce en un cierto grado de anticipabilidad de la decisión. La praxis, nos dice Schmitt, "se orienta fundamentalmente a dictar sentencias que sean previsibles" ${ }^{17}$.

13 Schmitt (2012) p. 14. En el mismo sentido, Schmitt señala que "Cualquier deducción que se haga a partir de una idea de derecho que pretenda una validez supratemporal es, o bien enemiga del contenido y, por tanto, carece de valor para la praxis, o bien tiene que renunciar a sí misma para hacerse útil a la praxis”. SCHMITT (2012) p. 110. También Larenz manifiesta una opinión similar al señalar que " Rectitud" no significa aquí una verdad intemporal, sino que rectitud para este orden jurídico y para este momento. En cuanto actividad metódicamente dirigida, que está orientada a conseguir enunciados «rectos», es decir, adecuados, la interpretación es una actividad científica solo si se libera de la estrechez del concepto cientificista de ciencia”. LARENZ (2001) pp. 311-312.

14 LARENZ (2001) p. 139.

15 Schmitt (2012) pp. 22-23.

16 SсHмiтt (2012) p. 104.

17 Schmitт (2012) p. 93. 
Cabe, sin embargo, preguntarse, ¿`cómo se logra esta previsibilidad y calculabilidad de la decisión jurídica? Schmitt responde de la siguiente manera: "una decisión judicial se tiene hoy por recta, si se puede esperar que otro juez (como un tipo empírico) hubiera decidido del mismo modo"1819. En otras palabras, el filósofo y jurista alemán responde a esta interrogante señalando que podemos considerar como "correcta" una interpretación de una ley (así como su consecuente aplicación) siempre y cuando sea posible aseverar que cualquier otro juez hubiese fallado en el mismo sentido.

Ahora, si bien la solución schmittiana parece prudente, ella hace surgir múltiples interrogantes, de las cuales cabe destacar las siguientes: a) ¿a qué se está refiriendo Schmitt cuando habla de un "juez empírico"? ¿Acaso está afirmando que todos los jueces fallan de la misma manera cuando son puestos frente a casos con características similares?, b) ¿por qué Schmitt asevera con tanta seguridad que una solución como la propuesta proporciona esta previsibilidad? ¿Qué tipo de calculabilidad es la que suministra? y c) ¿No se identifica la solución propuesta con el sistema conocido como common law en virtud de la cual los jueces han de fallar de acuerdo a los precedentes dejados por otros jueces?

De las primeras interrogantes (a) Schmitt se hace cargo directamente. En efecto, asevera que es evidente que no todos los jueces fallan de la misma manera ante casos similares y que sería absurdo el exigirle a los jueces que verificasen si efectivamente todos y cada uno de sus colegas fallarían de la misma manera en caso de ser puestos frente a un caso como el que él está tratando ${ }^{20}$. Por el contrario, lo que Schmitt dice es que el juez, al momento de fallar, debe hacer el ejercicio mental hipotético de "ponerse en el lugar" de otro juez de su mismo lugar y tiempo con el fin de verificar si lo que él pretende fallar sería razonable y explicable para este segundo juez hasta el punto de que este encontraría legítimo (y estaría dispuesto a) fallar de la misma manera. Es en este sentido en que el juez es empírico. El ejercicio sigue siendo ideal e hipotético, pero el "segundo juez" que utiliza el juez que se ve en la necesidad de fallar un caso no es uno de carácter supratemporal y omnipotente que va a dar una respuesta aplicable desde ese momento hasta la eternidad, sino que de un juez

18 Schmitт (2012) p. 65. Schmitt llama a este criterio el "principio de determinación del derecho". Cabe mencionar que Gadamer señala algo similar en Verdad y método, aunque claramente no con la profundidad y especificidad de Schmitt. En efecto, él señala que "el juez busca estar en armonía (in accord) con la «idea jurídica» en su mediación con el presente. Esto es, por su puesto, una mediación jurídica. Es el significado jurídico de la ley -y no el sentido histórico de la promulgación de la misma o de los casos particulares a los que se aplica- lo que está intentando comprender. De este modo, su orientación no es aquella del historiador, sino que está orientado hacia su propia historia, la cual es su presente”. GADAMER (2013) p. 337.

19 En el mismo sentido, Larenz señala que "Pero, aunque el juez sea inducido por el caso que ha de resolver a interpretar nuevamente un determinado término o una determinada norma jurídica, debe interpretarlos, por cierto, no solo precisamente para este caso concreto, sino de modo que su interpretación pueda ser efectiva para todos los demás casos similares. Si los tribunales interpretan la misma disposición en casos similares, ora de una manera, ora de otra, esto estaría en contradicción con el postulado de justicia que las cosas iguales deben ser igualmente tratadas, así como con la seguridad jurídica ambicionada por la ley”. LARENZ (2001) p. 310.

20 De hecho, Schmitt señala que la demostración de una cuestión como esta sería una confusión psicológica que invitaría a los jueces a ejercer la psicología de masas. Cf. Sснмітт (2012) pp. 107-109. 
sujeto a las mismas limitaciones intelectuales y temporales a las que se ve sujeto el juez que realiza el ejercicio ${ }^{21}$.

Respecto al segundo grupo de preguntas (b), parece atingente poner sobre la mesa la crítica que García Amado hace a soluciones como la propuesta por Schmitt, a saber, que con ellas "la hermenéutica filosófica se transmuta en pura metafísica con semejantes extrapolaciones a la ontología jurídica. Una muy difusa y evanescente ontología jurídica, que se sustenta en una no menos delicuescente ontología de lo social. [...] De tanto ser, acaba el derecho por ser nada"22.

Parece legítimo objetarle a Schmitt que, si bien su propuesta está cimentada sobre terreno teórico y metodológico firme, la alusión a una intersubjetividad "política" hace que la aplicación de su criterio legitimador sea imposible. La constante "mutabilidad" de la intersubjetividad y su inalcanzable determinación torna en quimérica su aplicación. En otras palabras, podría fácilmente argumentarse que la propuesta schmittiana cae justamente en aquello que pretendía evitar, a saber, en ser una bella y perfecta solución para la teoría, pero inservible para la praxis.

Ahora, si bien la objeción recién hecha parece suficiente como para destruir las pretensiones metodológicas de Schmitt, este autor fue lo suficientemente tenaz para darse cuenta de que su criterio daba lugar a lecturas de esta índole y se dio el trabajo de hacerse cargo de esta (aparente) debilidad de su argumento. Así, en Ley y juicio señala que "lo que generalmente se persigue en las formulaciones metodológicas es la seguridad teórica, es decir, una posición inequívoca que pueda hacer frente a todos los problemas que pertenecen al entramado de la cuestión, una respuesta que esté abierta a todas las dificultades; no se pretende obtener la seguridad propia de una tabla de logaritmos o de un mapa de carreteras que frecuentemente se citan como lo ideal. El postulado de la determinación del derecho es una abstracción consciente que se toma como punto de partida en la investigación metodológica para poder encontrar, a pesar de la multiforme realidad de la praxis, una fórmula que permita una respuesta, a partir de la cual se pruebe una y otra vez su justificación" ${ }^{\prime 2}$.

Es decir, tiene perfectamente claro que su propuesta no proporciona una seguridad "matemática", que no permite llegar a un grado de certeza apodíctica, pero al mismo tiempo asegura que no por ello su criterio es inservible. Por el contrario, Schmitt es de la idea de que una solución que se jacta de lograr un grado de certeza científicamente comprobable no es útil para la praxis, toda vez que no toma en cuenta que la realidad en caso alguno es

21 En este sentido, hay que tener en consideración que este criterio no es meramente ideal, toda vez que tiene manifestaciones concretas en la praxis. En efecto, Schmitt señala que algunas de las manifestaciones positivas que apoyan su criterio y orientan a la praxis hacia él son la colegiatura (tribunales conformados por 2 o más jueces) y la revisión de las sentencias en una segunda instancia. En efecto, Schmitt señala que estas dos instituciones permiten "una comunicabilidad (es decir, una conceptualización intelectual) del fundamento de la decisión, a través de las cuales la decisión se hace previsible y calculable, y se remite a la totalidad de la praxis judicial". Es decir, que son medios prácticos que buscan corregir las decisiones judiciales que se alejan de esta comunicabilidad intersubjetiva. SснмітT (2012) p. 102)

22 García Amado (2009) p. 199. Esta última referencia al ser está dirigida principalmente a la hermenéutica jurídico ontológica de Gadamer.

23 Schmitt (2012) pp. 155-156. 
constante, perfecta y/o cuantificable ${ }^{24}$. Antes bien, una solución útil para la vida práctica ha de tener en consideración que esta no puede ser medida a partir de parámetros científicos. La inabarcabilidad de la realidad hace imposible su perfecta conceptualización, por lo que un adecuado criterio legitimador de la decisión jurídica tiene que tener esto en consideración. Por lo tanto, hay que tener en cuenta que la "calculabilidad" y "previsibilidad" de la propuesta schmittiana no son aquellas de las ciencias exactas, sino que admiten un cierto grado de flexibilidad ${ }^{25}$, la cual podríamos graficar de la siguiente manera: como bien explica Derrida en Fuerza de $\mathrm{Ley}^{26}$, toda decisión jurídica implica un acto de violencia. Señala que "el derecho es siempre una fuerza autorizada, una fuerza que se justifica o que está justificada al aplicarse, incluso si esta justificación puede ser juzgada, desde otro lugar, como injusta o injustificable. La aplicabilidad, la «enforceability» no es una posibilidad exterior o secundaría que vendría o no vendría añadida, suplementariamente, al derecho" ${ }^{27}$. Es decir, toda aplicación de la ley a un caso concreto constituye un acto de violencia performativa que hace surgir el derecho propiamente tal. Asimismo, Derrida señala que "la justicia, por muy impresentable que sea, no espera" ${ }^{28}$. Esto es, cuando una situación de relevancia jurídica exige de la intervención de un juez, este necesariamente debe decidir ${ }^{29}$ y debe hacerlo con cierta rapidez.

En ese contexto, en lo que se refiere a la legitimidad de la decisión jurídica, es posible distinguir entre dos polos de nuda violencia: la mera subsunción del caso bajo la ley y el desasimiento ${ }^{30}$. Si bien ambos extremos han de ser evitados, la identificación antinómica de los mismos nos abre un espectro, un abanico de posibilidades en los que un menor grado de violencia es alcanzable. En ese sentido (y volviendo ya a Ley y juicio), tenemos que, si bien la solución schmittiana no es perfecta, proporciona una expectativa respecto al contenido de la decisión jurídica que permite reducir considerablemente el grado de violencia de la misma. Además, más allá no se puede ir. Un nivel de certeza apodíctica no es alcanzable en lo que se refiere a la legitimidad de una decisión jurídica, por lo que estimamos que esta solución es lo suficientemente buena (good enough, como dicen los angloparlantes), ya que proporciona los elementos suficientes para hacerse cargo de la historicidad a la que el derecho se ve expuesto (como bien veremos a continuación).

Por último, queda hacernos cargo de nuestra tercera interrogante (c), a saber, si acaso se identifica la solución propuesta por Schmitt con la metodología utilizada el common law

\footnotetext{
24 Dworkin es de la misma idea. En efecto, él señala que sería absurdo considerar que un texto legal, individualmente considerado, es en sí justo. Lo que hace a la ley justa es su reconfiguración mediante la interpretación (acto en el cual toman relevancia, por ejemplo, los principios. DWORKIN (1978) p. 89.

25 Además de que parte de la base que el contenido de dichos conceptos va variando de acuerdo al momento y lugar histórico en que se aplique, como ya veremos.

26 En razón de la finalidad y extensión del presente trabajo, utilizaremos el pensamiento de Derrida meramente de manera instrumental, por lo que no tematizaremos el deconstruccionismo ni haremos un análisis pormenorizado de su texto que lleva por título Fuerza de Ley.

27 DERRIDA (1992) p. 131.

28 DERrida (1992) p. 152

29 En este sentido, Schmitt afirma que un juez no puede abstenerse de fallas apelando al silencio o a la obscuridad de la ley. Cf. Sснмітт (2012) p. 23.

30 Entendiendo este concepto como el desprendimiento total del texto legal, desatenderlo absolutamente.
} 
en virtud de la cual los jueces han de fallar de acuerdo a los precedentes dejados por otros jueces. Al respecto, se ha de tener en consideración que la comunicabilidad de la decisión jurídica a otros jueces por medio de su razonabilidad y predictibilidad no lleva como corolario que un juez debe validar su decisión en los precedentes asentados por otros jueces que en el pasado se han visto enfrentados a situaciones similares. Por el contrario, y como bien señala Rasch, un criterio como el descrito le exige al juez "asegurarse de que su decisión se corresponde con la praxis jurídica actual y, en caso de desviarse de una opinión predominante, hacerlo siempre con argumentos tan perspicaces que su desviación se encuentra en el ámbito de la previsibilidad y la calculabilidad. Así, en determinadas circunstancias, las razones para tomar una decisión pueden tener [...] un significado creativo" ${ }^{31}$.

Es decir, la solución de Schmitt no se identifica con el sistema de los precedentes porque, a diferencia de esta última, su propuesta tiene como eje central la mutabilidad del contenido de la decisión de acuerdo a la historicidad del hombre.

En suma, lo que Schmitt busca es llevar a efecto el principio, muy lúcidamente descrito por Dworkin, según el cual toda persona que pertenece a una determinada comunidad tiene derecho a una cierta coherencia y consistencia en las decisiones jurídicas que se toman en la misma ${ }^{32}$. Es decir, toma en consideración la historicidad del hombre y la variabilidad de las distintas comunidades jurídicas, pero al mismo tiempo sostiene que cada época y comunidad tiene que ser consecuente en sus decisiones judiciales. A modo de ejemplo, tenemos que hace un siglo era razonable para la comunidad de jueces que las prostitutas no tenían la dignidad suficiente como para ser titulares de todos los derechos y garantías asegurados por la Constitución y las leyes. Sin embargo, esto ya no es así; hoy hay un cierto consenso de que toda persona es igual en dignidad y derecho. Pero sería sumamente injusto que hoy algunos casos fuesen solucionados tomando como premisa el paradigma de la falta de protección hacia las prostitutas, mientras que en otros se le reconociesen todos los derechos. Es por eso que Schmitt afirma que "si se quiere encontrar un criterio específico de corrección para la praxis en un determinado momento histórico como, por ejemplo, el actual, entonces la única posibilidad de encontrarlo descansa en la introducción del «otro juez» como un tipo empírico, y no en las citadas valoraciones populares" 33 .

El common law (o por lo menos la lectura clásica del mismo), en cambio, procede a cristalizar una solución, de tal manera que desde ese momento en adelante todos los jueces que se vean enfrentados a cosas similares deberán fallar de la misma manera. Es decir, una

\footnotetext{
31 RASCH (2004) pp. 101-102.here is a brief excerpt of the content:In Cultural Critique 57 (2004 El subrayado es nuestro. En el mismo sentido, Larenz señala que "la meta de la interpretación, según esto, solo puede ser la averiguación de lo jurídicamente decisivo hoy, es decir, de un sentido normativo de la ley. El sentido de la ley que se ha de estimar decisivo jurídicamente, no ha de identificarse con el querer o las concretas ideas normativas del legislador histórico, ni hacerse totalmente independiente de ello. Más bien es el resultado de un proceso de pensamiento en el que todos los momentos susodichos, es decir, tanto «subjetivos» como «objetivos», han de estar incluidos y el cual, como ya se ha dicho, en principio nunca termina”. LARENZ (2001) p. 315.

32 DWORKIN (1978) p. 126.

33 Schmitт (2012) p. 112.
} 
visión como esta en caso alguno se hace cargo de la mutabilidad de la decisión de acuerdo a los cambios que experimenta la praxis ${ }^{34}$.

En definitiva, con esta figura del "otro juez empírico" Schmitt introduce un criterio legitimador de la decisión jurídica que es ideal, toda vez que el ejercicio que ha de hacer el juez es hipotético, pero también empírico, ya que toma en consideración lo que ocurre en la praxis jurídica. Nos queda simplemente agregar que estimamos que la solución schmittiana es bastante buena, toda vez que la inclusión del sentido común del juez no es arbitraria, sino que validante y crítica a la vez. Esto porque el ejercicio hipotético puede o bien validar la decisión del juez o corregirla. Asimismo, estimamos que cumple su pretensión de ser útil para la praxis, toda vez que identifica algunas de las instituciones que permiten llevar esta elaboración teórica a la práctica, a saber, la colegiatura de los tribunales y la posibilidad de una doble instancia ${ }^{35}$.

\section{EL "FICCIONALISMO": DISTINCIÓN ENTRE INTERPRETACIÓN Y APLICACIÓN}

El criterio legitimador propuesto por Schmitt constituye una pieza fundamental para el criterio legitimador que pretendemos suministrar en el presente trabajo. De hecho, el nombre del mismo, a saber, ficcionalismo, recibe su nombre de la operación descrita por Schmitt, toda vez que lo que según este lo que ha de hacer el juez es hacer una ficción de que no es él quien está decidiendo sobre el caso particular puesto frente a sus ojos, sino que otro juez. Sin embargo, estimamos le falta a la elaboración teórica de Schmitt la especificación de ciertas condiciones que, junto a esta ficción que ha de hacer el juez, permiten legitimar una decisión jurídica en particular. Es por ello que, en lo sigue, nos preocuparemos de proporcionar dichas condiciones.

Según Gadamer (quien tiene un pensamiento bastante cercano al de Schmitt), una ley no existe para ser comprendida históricamente, sino para tener validez jurídica por medio de su concreción a través de la interpretación. De manera similar, el evangelio no

\footnotetext{
34 Cabe mencionar, empero, que tampoco es que el common law sea incompatible con una comprensión del derecho como devenir. En efecto, y como bien señala Dworkin, el juez del common law puede o bien actuar como una máquina subsumidora (el precedente como regla y el caso como aquello que ha de calzar), o como un miembro que, a partir de su función, reflexiona sobre (y a su vez va determinando) el contenido de los conceptos jurídicos. Es decir, los jueces aportan activamente en la determinación de lo que se entiende como equitativo, por ejemplo. DwORKIN (1978) p. 128.

35 Cabe tener en consideración que William Rasch señala que la propuesta de Schmitt acerca de la legitimidad de las decisiones jurídicas se asemeja bastante al juicio reflexionante kantiano. En efecto, nos dice que para Schmitt esta legitimidad debe buscarse en sentido ascendente, es decir a partir del caso concreto para luego llegar a la regla universal, y no al revés. En sus palabras, "al ejercer sus funciones, realiza una especie de juicio reflexionante, ascendiente de lo particular o lo universal, o más bien construyendo lo universal en respuesta a lo particular, por medio de un mecanismo que tiene, no sorprendentemente, un parecido a ciertos aspectos del juicio estético kantiano”. RASCH (2004) pp. 99-100.here is a brief excerpt of the content:In Cultural Critique 57 (2004 En el mismo sentido, en el "Estudio preliminar" que hace a Ley y juicio, Monserrat Herrero señala que "el mismo problema al que apunta Kant es el que intenta resolver Schmitt en Ley y Juicio, una ciencia práctica no puede prescindir de la regulación de los casos particulares, en otro caso sería una simple teoría”. HERRERO (2012) p. LII.
} 
existe para ser tenido como un mero documento histórico, sino que para ser tomado en un sentido tal que lleve a la práctica su efecto salvífico. Esto implica que el texto, ya sea la ley o el evangelio, si quiere comprenderse adecuadamente es decir, de acuerdo a sus pretensiones debe ser comprendido en cada momento, en cada situación concreta, de una manera diferente. La comprensión aquí siempre es aplicación ${ }^{36}$. En un sentido similar, Hart señala que la interpretación permite eliminar la indeterminación de los conceptos jurídicos contenidos en las leyes ${ }^{37}$. Es decir, para Hart "la función de la interpretación jurídica es precisamente la de eliminar esa situación de indeterminación que presentan las normas generales en algunos casos, y por eso resulta vinculado el concepto de interpretación con el de la aplicación de esas normas a los casos individuales difíciles" ${ }^{38}$. En definitiva, para estos autores la interpretación jurídica (así como la teológica en el caso de Gadamer) no se ha de hacer en abstracto, sino que teniendo en consideración el caso concreto. Esto significa que el sentido y alcance del texto legal se configura y renueva en cada caso de acuerdo a las particularidades del conflicto de relevancia jurídica que hace necesario acudir a la norma.

Para Gadamer, entonces, interpretar es aplicar; es decir la praxis determina la interpretación, toda vez que esta se configura a partir de la aplicación (y por ello el derecho y la teología son ejemplares en esta materia). Ahora, si bien estimamos que Gadamer está en lo correcto al hacer tal afirmación, la misma parece no considerar el fenómeno jurídico en su totalidad. En efecto, y como bien señala Larenz en su Metodología de la Ciencia del Derecho: "Gadamer desatiende, sin embargo, la función regulativa de la norma. El jurista pregunta por la «vinculabilidad normativa del sentido a comprender» porque él contempla la norma, con razón, como la regla por la que tiene que medir el «caso». La cuestión es entonces esta: ¿Cómo es posible esto cuando en verdad cuando la regla consigue su última determinación de contenido solo en el proceso de su «aplicación»? [...] Una «regla» exige ser aplicada del mismo modo a todos los casos que han de ser medidos por ella. Esto no parece ser posible si su contenido, que Gadamer toma expresamente en consideración también para la interpretación jurídica, «tiene que ser entendido de nuevo y de otro modo en cada situación concreta" 'es decir, para cada caso particular"'39.

En otras palabras, Larenz señala que, si bien Gadamer está en lo cierto en lo que se refiere a la relevancia de la aplicación en la hermenéutica jurídica, la configuración de la solución a la que llega el juez no se hace en el vacío, sino que se hace a partir de un texto legal. Es decir, aun cuando es efectivo que la interpretación que hace el juez a la luz del caso puesto frente a sus ojos es en cierto modo "creadora", esta creación no se produce ex nibilo, sino que sobre la base de un marco regulatorio dado ${ }^{40}$.

Llegados a este punto, parece imperativo el considerar lo dicho por Larenz para proporcionar un criterio de corrección de la decisión jurídica. En ese contexto, estimamos necesario distinguir dos etapas o procesos interpretativos que el juez realiza a la hora de

\footnotetext{
36 Cf. Gadamer (2013) pp. 319-320.

37 Cf. НART (1961) pp. 121-132.

38 URSÚA (2004) p. 261.

39 LARENZ (2001) p. 202.

40 En el mismo sentido, el jurista Emilio Betti señala que "ningún jurista hoy, al considerar el derecho positivo, siente que podría prescindir del mismo. La razón de ello radica en que el hacer esto sería similar a intentar ver y construir el fenómeno jurídico sin nuestros ojos”. BЕTті (2015) p. 110.
} 
tomar una decisión para un caso concreto: la interpretación jurídica en abstracto y aquella que se realiza en concreto, las cuales, a su vez, están orientadas a fines distintos: la legalidad y la corrección. Así, en la interpretación en abstracto de lo que se preocupa el juez es de verificar si acaso el sentido y alcance que le quiere dar a una ley se condice con el texto escrito de la misma, mientras que en aquella que realiza en concreto se preocupa de si acaso a nivel fáctico su decisión es correcta. Ahora, se ha de tener en consideración que esta distinción la hacemos para efectos pedagógicos, toda vez que ambas interpretaciones se encuentra íntimamente ligadas, de tal manera que no hay una sin la otra ${ }^{41}$.

Hecha esta salvedad, pasemos a explicar estas etapas de la interpretación. Como bien afirma Derrida, "el derecho es el elemento del cálculo y es justo que haya derecho; la justi-

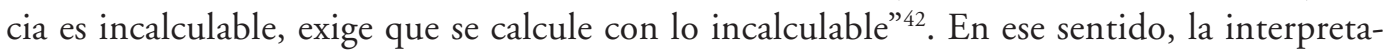
ción que hace el juez en abstracto se preocupa de la legalidad, de si acaso se está actuando dentro del marco regulatorio dado, pero todavía no de la corrección. Cabe, sin embargo, preguntarse ¿acaso no estamos cayendo justo en aquello que criticamos, a saber, que la aplicación no es un mero suplemento al conocimiento en abstracto que se adquiere de la ley? A esto respondemos que sí y no. Sí porque efectivamente estimamos que un cierto conocimiento teórico en abstracto de la ley es necesario en la interpretación, y no por dos razones: primero porque no creemos que haya solo una interpretación correcta en abstracto; segundo, porque no estimamos que una vez adquirido este conocimiento la operación que le corresponde al juez es de mera subsunción del caso bajo dicha interpretación ideal. Ahondemos un poco en esto: como bien señala Larenz, "«interpretar» un texto quiere decir [...] decidirse por una entre muchas posibles interpretaciones" ${ }^{\prime 3}$. Es decir, no es que la interpretación en abstracto va a arrojar una única posible interpretación de una ley, sino que meramente va a proporcionar un abanico de (numerosas) posibles (y legítimas) interpretaciones que se encuentran ajustadas a derecho. Así, la labor del juez no consiste en una mera subsunción, sino que, atendiendo las particulares características del caso puesto frente a él, le corresponde elegir la interpretación más adecuada. Ahora, ¿`cómo elige el juez? Puesto de otra manera, la legalidad nos proporciona meramente los límites del campo de juego en el que el juez puede moverse libremente, pero ¡cómo determina este cuál de las interpretaciones del espectro de posibilidades que se abre a partir del texto es la más adecuada para el caso concreto? Al respecto, es útil tener consideración lo dicho por Derrida sobre el asunto, a saber, que "si me conformo con aplicar una regla justa sin espíritu de justicia y sin inventar cada vez, en cierta manera, la regla y el ejemplo, actuaría quizás al amparo del derecho, con arreglo al derecho objetivo, pero no sería justo" ${ }^{44}$. En otras palabras, al juez no le basta con la mera legalidad para lograr la corrección de una decisión, sino que requiere que esta

\footnotetext{
41 En efecto, el juez no va a entrar a revisar si un texto legal "aguanta" la interpretación que quiere darle sin antes haberse enfrentado a las particularidades del caso en concreto, ni tampoco (en principio) va a tomar una decisión para un caso concreto si no tiene un marco regulatorio que le permita sustentar su decisión.

42 Derrida (1992) p. 142. Hay que tener en consideración que, a diferencia de Derrida, y como bien explicaremos en breve, hemos preferido hablar de "corrección" en vez de "justicia".

43 LARENZ (2001) p. 192.

44 DERRIDA (1992) p. 143.
} 
sea justa; ¿cómo se logra esto? Mediante la reinvención de la norma de acuerdo a las particulares características del caso puesto frente al juez ${ }^{45}$.

Ahora, a pesar de que Schmitt y Derrida hablan de "justicia”, nosotros utilizaremos el término "corrección o rectitud de la decisión jurídica", toda vez que estimamos que la inclusión casual de un concepto tan controversial como lo es la justicia no corresponde, especialmente dada la finalidad y la extensión del presente trabajo ${ }^{46}$. Asimismo, queremos volver a insistir en que, para nosotros, al igual que para Larenz, "no existe, sin embargo, una «interpretación absolutamente recta» en el sentido de que sea tanto definitiva como válida para todos los tiempos. [...] < En efecto,> «rectitud» no significa aquí una verdad intemporal, sino que rectitud para este orden jurídico y para este momento" 47 .

Hecha esta salvedad, sigamos dotando de contenido el concepto de "rectitud de la decisión jurídica”. Como bien acabamos de mencionar, para considerar como recta una decisión jurídica, el juez no debe limitar su actividad a la mera subsunción del caso bajo el conocimiento abstracto, sino que debe "reinventar", tomando como base el texto escrito (y sus múltiples posibilidades de aplicación), la ley para cada caso particular. En palabras de Derrida, "para ser justa, la decisión de un juez, por ejemplo, no debe solo seguir una regla de derecho o una ley general, sino que debe asumirla, aprobarla, confirmar su valor, por un acto de interpretación reinstauradora como si la ley no existiera con anterioridad, como si el juez la inventara él mismo en cada caso. Cada ejercicio de la justicia como derecho solo puede ser justo si se trata de un "fresh judgment» [...]. Este «fresh judgment» puede y debe ser conforme a una ley preexistente, pero la interpretación reinstauradora, reinventiva y libremente decisoria, responsable, del juez, requiere que su «justicia» no consista solamente en la conformidad, en la actividad conservadora y reproductora de la sentencia” ${ }^{48}$.

Lo anterior, si bien deja en claro la (necesaria) mutabilidad de la cual es susceptible un texto legal en la interpretación, no responde la pregunta contra la cual estamos arremetiendo en el presente trabajo, a saber, ¿cómo determinamos si esta reinvención de la ley que hace el juez es legítima? La respuesta a esta pregunta, como ya adelantamos, la encontramos en el ficcionalismo. Es decir, una vez que el juez se cerciora de que su interpretación es legal, en el sentido de que se encuentra dentro del espectro de posibilidades que abre el texto escrito de la ley, debe atestiguar que el resto de la comunidad jurídica -en específico los jueces- encuentra razonable y prudente su decisión mediante el ejercicio hipotético ya explicado, el cual permite llegar a la convicción - subjetiva $^{49}$ - de que cualquier otro juez

45 Cf. Sснмiтt (2012) p. 120.

46 En efecto, el hacer fe a lo que la justicia es requeriría un estudio pormenorizado de prácticamente todos los grandes autores de filosofía práctica, además de que exigiría un esclarecimiento de lo que Derrida entiende por justicia, cuestión que supera con creces la finalidad de esta investigación.

$47 \quad$ LARENZ (2001) pp. 311-312.

48 DERrida (1992) p. 149.

49 Insistimos, siguiendo a Rasch, que el carácter subjetivo del criterio legitimador se asemeja bastante a lo señalado por Kant en la Analítica de lo Bello de su Crítica de la Facultad de Juzgar. En efecto, Kant comienza señalando que "el juicio de gusto no es, entonces, un juicio de conocimiento y, por consiguiente, tampoco lógico, sino estético; se entiende por este aquel cuyo fundamento de determinación no puede ser de otro modo sino subjetivo. Toda relación de las representaciones, aun de las sensaciones, puede, empero, ser objetiva (y entonces significa ella lo real de una representación empírica); únicamente no lo es la relación con el sentimiento de 
hubiese fallado en el mismo sentido. En un sentido similar, Dworkin, al incorporar la figura del juez Hércules, señala que una decisión jurídica es legítima solo en cuanto responda se encuentre validada por las convicciones morales (y políticas) subyacentes en un ordenamiento jurídico en particular ${ }^{50}$.

En síntesis, el criterio legitimador aquí propuesto -el ficcionalismo- consta de dos etapas: primero se debe revisar la legalidad de la decisión; es decir, el juez debe verificar si el texto legal "aguanta" la interpretación que se quiere hacer de él para un caso concreto ${ }^{51}$. Luego se debe revisar la rectitud o corrección de dicha interpretación mediante el ficcionalismo propiamente tal, por ponerlo de alguna manera; o sea, el juez debe realizar el ejercicio hipotético antes explicado y comprobar si su interpretación es razonable, convicción a la que llegará si logra concluir que cualquier otro juez (empírico) hubiese fallado de la misma manera en caso de ser puesto frente al mismo caso. No nos queda sino agregar que el criterio aquí propuesto encuentra su fundamento, como bien lo ilustra Dworkin, no en la sabiduría de las decisiones de los jueces, sino que en que es justos que los casos similares sean tratados de manera similar ${ }^{52}$

\section{IV. ¿ES SUFICIENTE EL FICCIONALISMO?}

Luego de propuesto nuestro criterio legitimador cabe preguntarse, ¿es suficiente? Puesto de otro modo, ¿el ficcionalismo realmente permite legitimar una decisión jurídica? La respuesta a esta pregunta depende, en primera instancia, de qué entendemos por suficiencia. Si para considerar como suficiente un criterio creemos que este debe proveer una certeza apodíctica, nuestra respuesta sería negativa. En efecto, y como ya hemos señalado a lo largo de este trabajo, el ficcionalismo no pretende dar una respuesta atemporal y eterna en lo que se refiere al contenido de la decisión jurídica, por lo que en caso alguno es suficiente en este sentido. Sin embargo, si consideramos la suficiencia como "útil para la praxis", entonces nuestra respuesta sería positiva. Consideramos que el ficcionalismo es útil para la praxis en el sentido que proporciona un criterio legitimador para una comunidad política determinada en un tiempo determinado, facilitando al mismo tiempo un punto medio entre la inmutabilidad de los textos legales y la mutabilidad histórica de los seres humanos. En ese sentido, estimamos que este criterio permitiría tener una cierta objetividad no "eterna", "única" o "cristalizada", sino que mudable de acuerdo a la historicidad intrínseca del Dasein: una objetividad "fluidificada" 33.

placer y de displacer, por medio de la cual nada es designado en el objeto, sino en la cual el sujeto se siente a sí mismo tal como es afectado por la representación" ( $\mathrm{KrU}$, 5:203). Hemos utilizado la siguiente traducción de la Crítica de la Facultad de Juzgar: Kant (1992)

50 DwORKIN (1978) p. 126.

51 Menester es mencionar que tanto Derrida como Schmitt son partidarios de la solución jurídica contra legem en caso de exigir la justicia una solución en tal sentido. Pondremos sobre la mesa esta problemática en el apartado $\mathrm{V}$ del presente trabajo.

52 DWORKIN (1978) p. 113.

53 Tomamos este concepto prestado de: Vattimo (2002) p. 67. 
Por otra parte, además de tener la gracia de ser un criterio acorde al ser que en cada caso somos nosotros mismos, consideramos que el ficcionalismo es un aporte en lo que se refiere al método. En efecto, aun cuando este criterio no es metódico en el sentido ilustrado, donde, como bien señala Kant, "la unidad sistemática es aquello que convierte el conocimiento ordinario en ciencia, es decir, los transforma de mero agregado del conocimiento en un sistema" ${ }^{54}$, de igual manera constituye un aporte, toda vez que le proporciona al juez un modelo al cual acudir a la hora de solucionar un conflicto de relevancia jurídica. Además, como bien señala Larenz, "la Metodología no puede tratar de establecer reglas fijas que solo fuera preciso seguir para caminar seguro en la aplicación de normas jurídicas. La interpretación, y todo lo que esta lleva consigo, no es una actividad que pudiera será realizada según reglas fijas; para ello es también precisa siempre la fantasía creadora del intérprete" ${ }^{\prime 5}$.

En otras palabras, la inconmensurabilidad de la realidad jurídica hace imposible la reducción de su metodología a una serie de reglas que aseguren el éxito. El mundo jurídico está en constante devenir y su metodología, para ser exitosa, necesariamente ha de tener esto en consideración -cuestión que de hecho sucede en el ficcionalismo-.

Ahora, ¿es un criterio perfecto? Claramente no. Pero más allá no podemos llegar ${ }^{56}$. Los seres humanos no somos dioses, por lo que no tenemos la posibilidad de acceder a conocimiento de carácter eterno. Nos tenemos que contentar, por lo tanto, con aquello que sí podemos conocer. Hay que tener en cuenta, además, que no por eso este criterio deja de ser lo suficientemente bueno (good enough). En efecto, las manifestaciones que este criterio actualmente tiene en el mundo jurídico -la colegiatura de los tribunales y la posibilidad de una doble instancia- han demostrado ser lo suficientemente buenas en lo que se refiere al control de la corrección ${ }^{57}$. Además, este criterio tiene la virtud que permite separarse tanto de la violencia de la mera subsunción y de aquella que proviene del desasimiento.

Para terminar este apartado, nos queda solo poner sobre la mesa el carácter político de este criterio. En efecto, el apelar a una intersubjetividad -aunque en este caso limitada a la comunidad de los jueces ${ }^{58}$ y señalar que el asentimiento de la comunidad tiene un efecto en la determinación del contenido del criterio legitimador tiene un marcado carácter político ${ }^{59}$. En efecto, el tomar como premisa que las ideas y convicciones de una comunidad determinan el contenido de las categorías (en este caso jurídicas) que se utilizan, implica

\footnotetext{
54 A 832, B 860. Hemos utilizado la siguiente versión de la Crítica de la Razón Pura: Kant (2013).

55 LARENZ (2001) pp. 239-240.

56 En caso alguno esto significa que este criterio no es perfectible. En efecto, sobre el mismo se pueden hacer una serie construcciones que pueden ayudar al juez a legitimar una decisión jurídica.

57 Aun cuando podrían ser mejores en lo que se refiere a la posibilitación del devenir del derecho, es decir, en la facilitación de la evolución del derecho por vía hermenéutica

58 Atria, tomando como base a autores pertenecientes a la tradición anglosajona, indica que las ideas políticas que sirven de sustento a las decisiones jurídicas no deben solo ser sostenidas por la comunidad jueces, sino también por los políticos (profesionales) y por quienes practican el derecho. Atria (2002) p. 372.

59 Si tomamos en consideración la relación entre el criterio legitimador de Schmitt y la Crítica de la Facultad de Juzgar de Kant, tenemos que el nexo entre ambos es bastante claro. En efecto, y como bien señala Arendt, "los vínculos entre las dos partes (de la Crítica del Juicio) están más estrechamente conectados con lo político de lo que están cualquiera de las otras Críticas. El más importante de estos vínculos radica, en primer lugar, en
} 
reconocer que como sociedad utilizamos un complejo de relaciones normativas cuyo contenido es susceptible de ser redefinido de acuerdo a las necesidades de la praxis ${ }^{60}$. Es decir, el contenido de una "ley es una construcción social, y por lo tanto debe haber un cierto grado (al menos tácito, aunque no necesariamente consciente) de consenso entre los ciudadanos y quienes practican el derecho" ${ }^{1}$. Esto, como bien lo explica Dworkin, tiene como corolario que las decisiones de los jueces no son exclusivamente jurídicas, sino que también políticas, lo que a su vez implica un grado de responsabilidad para los jueces en la conformación de la comunidad misma ${ }^{62}$. Más aún, si, siguiendo a Gadamer ${ }^{63}$, extendemos la manera en que opera la hermenéutica jurídica al conocimiento práctico en general, el carácter político de este criterio queda aún más claro. Sin embargo (y lamentablemente), esta no es la instancia para profundizar en este asunto, sino que meramente para explicitarlo. Es por ello que nos limitaremos a señalar que, como bien dice Rasch, el carácter político de este criterio trae como consecuencia que "lo que surge es una comunidad, y no solo una comunidad, sino que una pluralidad de comunidades, cada una legitimando sus propias decisiones sobre la base de una universalidad que solo puede ser performada (performed) y nunca fundamentada (grounded). Lo que surge es el mundo tal como si siempre hubiese existido. ¿Qué puede ser más natural que eso?”64.

\section{JUSTICIA CONTRA LEGEM}

No nos queda sino poner sobre la mesa una problemática que puede surgir a partir de nuestro criterio de corrección de la decisión jurídica, a saber, el de la justicia fuera de la legalidad. En efecto, somos de la idea de que para considerar que una decisión jurídica es correcta esta debe enmarcarse dentro de la legalidad y debe ser justa de acuerdo al ejercicio hipotético del "otro juez". Sin embargo, y como bien es posible observar en el día a día de la praxis judicial, hay decisiones que para ser justas requieren omitir la legalidad o directamente ir en contra de la misma -como ocurrió, por ejemplo, en los juicios de Núremberg ${ }^{65}$ luego de la segunda guerra mundial-.

que en ninguna de las dos partes habla Kant del hombre como ser inteligible o cognitivo. La palabra verdad no aparece”. ARENDT (1984) pp. 517-518.

${ }^{60}$ Con el concepto norma nos referimos, como bien lo explica Crowell, a "cualquier cosa (anything) que sirve como standard de éxito o fracaso de cualquier tipo. [...] Así, un estatuto legislado es una norma, como también lo son las reglas de un juego como lo es el ajedrez o el baseball; pero las reglas tácitas (unspoken rules), condiciones de satisfacción, costumbres de carácter cultural, lo que «normalmente» se hace [...] son también normas". Crowell (2013) p. 2. En un sentido similar, Atria dice que "la idea de «normalidad» es el vínculo entre la evolución de las ideas sobre la ley y el contenido de la misma”. Atria (2002) p. 352.

61 Atria (2002) p. 372.

62 DwORKIN (1978) pp. 87-88.

63 Gadamer señala que "cuando un juez considera que tiene el derecho a suplir el sentido original de un texto legal, está haciendo exactamente lo que tiene lugar en toda otra comprensión”. GADAMER (2013) p. 349.

64 Rasch (2004) p. 103.

65 Aun cuando estos juicios importan un problema mucho más amplio, el establecimiento de tribunales especiales para juzgar crímenes cometidos con anterioridad a su creación no sirve de modo ejemplar, toda vez que se trata de algo contrario a la ley, pero necesario en pos de la justicia (por lo menos en esa situación en específico). 
Cabe, entonces, preguntarse, ¿qué hacemos en estos casos con nuestro criterio de corrección? Si bien una respuesta lo suficientemente fundada requiere de un análisis previo de no menor envergadura, de manera tentativa nos atrevemos a postular que en los casos en que la justicia requiere ir en contra de la legalidad se debe preferir a la primera sobre la segunda. En efecto, y siguiendo a Schmitt, "la fórmula contiene una solución sin contradicciones para las complicaciones que se derivan de que, de un lado, la autoridad de la ley debe quedar protegida, pero, de otro, a veces habrá que tomar decisiones praeter y en ocasiones contra legem, las cuales, a pesar de que apenas puedan considerarse acordes a las fuentes, pueden ser consideradas rectas [...]. Que la «legalidad» de la decisión no deba identificarse con su corrección, no significa que quede suspendida toda regla objetiva y que entonces todo termine dependiendo de la subjetividad del juez 'si la fórmula, además, explica el significado de los precedentes y es capaz de ponerlos en sintonía con el resto de sus explicaciones, entonces prueba su justificación como principio normativo de la praxis judicial actual"'66.

Es decir, no se ha de creer que por preferir la corrección por sobre la legalidad la decisión jurídica pasa a estar en manos del arbitrio del juez. Por el contrario, el ejercicio hipotético que hace el juez para verificar si su decisión es correcta de acuerdo a la praxis de lugar y tiempo es suficiente para dar seguridad jurídica y una cierta objetividad -tomada esta palabra en el sentido de la previsibilidad antes explicada- incluso en aquellos casos que esta decisión vaya en contra de la ley.

\section{CONCLUSIONES}

Ciertamente lo que se ha sugerido como respuesta ha sido meramente un esbozo de lo mucho que lo que exige el tema mismo. Sin embargo, estimamos que ella cumple el objetivo que la investigación se propuso, a saber, el formular un criterio de corrección de la decisión jurídica tomando como base los presupuestos epistemológicos/existenciales de la hermenéutica. Asimismo, somos de la idea que es posible destacar las siguientes virtudes del criterio propuesto:

1. Se trata de un criterio que no solo tiene solidez teórica, sino que también resulta útil a nivel práctico.

2. Pone sobre la mesa la relevancia de la comunidad de jueces en la configuración del derecho, así como la responsabilidad que conlleva la interpretación de los textos legales.

3. Si, como Gadamer, consideramos que la interpretación jurídica da cuenta de cómo opera el saber práctico en general, tenemos que este criterio da pie para investigar la posibilidad de un criterio similar para la decisión práctica (moral, política, etc.) ${ }^{67}$.

\footnotetext{
SchmitT (2012) p. 100.

Aun cuando una investigación como la descrita debería enfrentarse a la tarea de determinar hasta qué punto la intersubjetividad puede servir como criterio legitimador en sede de filosofía práctica.
} 
Por último, menester nos parece recalcar la incompletitud de este trabajo -0 , si queremos ver el vaso medio lleno, la posibilidad de complementación y continuidad del mismo-. En efecto, este es meramente un punto de partida. Siguiendo las poéticas palabras de Hegel, diremos de este trabajo que "del mismo modo que no se construye un edificio cuando se ponen sus cimientos, el concepto del todo a que se llega no es el todo mismo. No nos contentamos con que se nos enseñe una bellota cuando lo que queremos ver ante nosotros es un roble, con todo el vigor de su tronco, la expansión de sus ramas y la masa de su follaje. Del mismo modo, la ciencia, coronación de un mundo del espíritu, no encuentra su acabamiento en sus inicios" 68 .

\section{BIBLIOGRAFÍA CITADA}

Arendt, H. (1984): La vida del epiritu. El pensar, la voluntad y el juicio en la filosofía y en la politica (Barcelona, Centro de Estudios Constitucionales).

Atria, F. (2002): “The Powers of Application”, Ratio Juris, vol. 15, N4: pp. 347-376.

BetTi, E. (2015): General Theory of Interpretation, Volumen 1 (CreateSpace Independent Publishing Platform).

Crowell, S. (2013): Normativity and Phenomenology in Husserl and Heidegger (New York, Cambridge University Press).

Derrida, J. (1992): "Fuerza de ley: el fundamento místico de la autoridad", Doxa, $\mathrm{N}^{\circ} 11$ : pp. 129-191.

Dworkin, R. (1978): Taking rights seriously (Cambridge, Harvard University Press).

Gadamer, H-G. (2013): Truth and Method (London \& New York, Bloomsbury).

García Amado, J.A. (2009): "Filosofía hermenéutica y derecho", Azafea: Revista de Filosofía, $\mathrm{N}^{\circ}$ 5: pp. 191-211.

Hart, H.L.A. (1961): The Concept of Law (Oxford, Oxford University Press).

Hegel, G.W.F. (2012): Fenomenología del espiritu (Mexico D.F., Fondo de Cultura Economica).

Heidegger, M. (2013): Nietzsche (Barcelona, Ariel).

Herrero, M. (2012): "Estudio preliminar" en Schmitt, C., Posiciones ante el derecho (Madrid: Editorial Tecnos).

Husserl, G. (1955), Recht und Zeit (Frankfurt, V. Klostermann).

Kant, I. (1992): Crítica de la facultad de juzgar (Caracas, Monte Avila Editores).

Kant, I. (2013): Crítica de la Razón Pura (México D.F., Taurus).

Larenz, K. (2001): Metodología de la ciencia del derecho (Barcelona, Ariel).

Rasch, W. (2004): "Judgment: The Emergence of Legal Norms", Cultural Critique, vol. 57, $\mathrm{N}^{\circ}$ 1: pp. 93-103.

Schmitt, C. (2012): "Ley y juicio. Examen sobre el problema de la praxis judicial" en HeRrero, Montserrat (trad.), Posiciones ante el derecho (Madrid, Editorial Tecnos).

Thulstrup, Niels. (1967): "An Observation Concerning Past and Present Hermeneutics", Orbis Litterarum, No 22: pp. 24-44.

68 Hegel (2012) p. 12. 
Pérez LASSERRE, Diego —El "otro juez" y la hermenéutica: el ficcionalismo como criterio legitimador de la decisión jurídica

URSÚA, J. F. (2004): “ Interpretación jurídica: una propuesta de esquematización de planteamientos", Isonomía, No 20: pp. 255-275.

Vatтimo, G. (2002): Introducción a Heidegger (Barcelona, Gedisa).

\section{NORMAS CITADAS}

LEY N 19.947 (17.5.2004), Establece nueva ley de matrimonio civil. 